\title{
FIRST RESPONDER TRAINING: SUPPORTING COMMERCIALIZATION OF HYDROGEN AND FUEL CELL TECHNOLOGIES
}

\author{
N.F. Barilo ${ }^{1}$, J.J. Hamilton ${ }^{2}$, and S.C. Weiner ${ }^{3}$ \\ ${ }^{1}$ Pacific Northwest National Laboratory, Richland, WA 99354, USA, nick.barilo@pnnl.gov \\ ${ }^{2}$ California Fuel Cell Partnership, West Sacramento, CA 95691, USA, jjhamilton@ cafcp.org \\ ${ }^{3}$ Excelsior Design, Inc., Richland, WA, USA, sc.weiner@ comcast.net
}

\begin{abstract}
A properly trained first responder community is critical to the successful introduction of hydrogen fuel cell applications and their transformation in how we use energy. Providing resources with accurate information and current knowledge is essential to the delivery of effective hydrogen and fuel cell-related first responder training. The California Fuel Cell Partnership and the Pacific Northwest National Laboratory have over 15 years of experience in developing and delivering hydrogen safety-related first responder training materials and programs. A National Hydrogen and Fuel Cell Emergency Response Training Resource was recently released (http://h2tools.org/fr/nt/). This training resource serves the delivery of a variety of training regimens. Associated materials are adaptable for different training formats, ranging from high-level overview presentations to more comprehensive classroom training. This paper presents what has been learned from the development and delivery of hydrogen safety-related first responder training programs (online, classroom, hands-on) by the respective organizations. The collaborative strategy being developed for enhancing training materials and methods for greater accessibility based on stakeholder input will be discussed.
\end{abstract}

\subsection{INTRODUCTION}

A properly trained first responder community is critical to the introduction of hydrogen fuel cell applications and their transformation in how we use energy. Resources that provide accurate information and current knowledge are essential to effective hydrogen and fuel cell related first responder training programs. $\mathrm{H}_{2} \mathrm{USA}$ (http://h2usa.org), a public-private collaboration with a mission to promote the commercial introduction and widespread adoption of fuel cell electric vehicles (FCEV) across America, recognizes this imperative. Having properly trained first responders has been identified by $\mathrm{H}_{2} \mathrm{USA}$ as a key barrier to ensuring a safe transition to fuel cell vehicles and hydrogen infrastructure and paving the way for broader public acceptance.

Hydrogen and fuel cell emergency response resources have been included in multiple training programs in the United States. Examples include the U.S. Department of Energy's Hydrogen Emergency Response Training for First Responders, developed and managed by Pacific Northwest National Laboratory (PNNL), and a program developed by the California Fuel Cell Partnership (CaFCP) for the California Office of the State Fire Marshal. Additionally, emergency responder education for alternative fueled and electric vehicles, including hydrogen fuel cell vehicles, has been developed and delivered by the National Fire Protection Association (NFPA) and other organizations around the United States. [1]

To help advance first responder training efforts and remove knowledge barriers, PNNL in collaboration with others has developed a three-tiered hydrogen safety education program using the Occupational Safety and Health Administration and National Fire Protection Association frameworks for hazardous materials emergency response training. [2,3] The Occupational Safety and Health Administration (OSHA) and NFPA use a tiered approach for training emergency responders on appropriate responses to incidents involving hazardous materials. Since emergency responders are already familiar with this 
approach, the same approach for hydrogen safety training has been utilized. The four tiers of training correspond to four levels of specialization: awareness, operations, technician, and specialist. The first two levels, awareness and operations, are discussed in Section 2.

\subsection{AWARENESS-LEVEL TRAINING - AN ONLINE RESOURSE}

Awareness-level hydrogen safety training is intended for fire, law enforcement, and emergency medical personnel who may witness or discover a hydrogen release and must initiate an emergency response sequence. The course, Introduction to Hydrogen Safety for First Responders (http://www.hydrogen.energy.gov/firstresponders.html), was launched in January 2007 and is divided into modules that cover hydrogen basics, transport and storage, hydrogen vehicles, hydrogen dispensing, stationary facilities, codes and standards, and emergency response [4, 5]. After completing all of the modules, the user takes a comprehensive quiz on the course material and receives a certificate of completion if they score $80 \%$ or higher. The course also includes a library of supporting documents and videos, as well as links to related websites.

The engagement of stakeholders and other subject matter experts was integral to developing the online material. Two pilot courses were held at the Volpentest HAMMER Federal Training Center, Richland, WA in 2005, with approximately 40 participants including fire fighters, trainers, police, fire marshals, and code enforcement officials. A broad review by the hydrogen and emergency response community was conducted in the summer 2006 with the purpose of improving the course materials prior to launch.

Since the online course was launched in January 2007, there have been more than 32,000 unique visitors to the website. The site still averages almost 300 unique visitors each month from nearly every state and many foreign countries and user feedback has always been encouraging:

- "Very informative; we all need to see this."

- "Did this during my lunch hour and really enjoyed it. Thank you for a pleasant learning experience."

Typical users include the fire prevention and protection community, fire fighters, fire department education coordinators, fire marshals, fire plan examiners/inspectors, code officials, law enforcement officials, and representatives from industry, universities, and the military and non-profit organizations.

\subsection{COMBINING CLASSROOM CURRICULUM AND LIVE-FIRE TRAINING}

The operations-level curriculum, Hydrogen Emergency Response Training for First Responders, focuses on teaching first responders how hydrogen and fuel cell vehicles are different from conventional fuels and vehicles, and how they are the same. The operations-level course is divided into modules that cover hydrogen and fuel cell basics, hydrogen vehicles, stationary facilities, and emergency response [6]. The classroom setting also provides an opportunity for participants to be divided into teams, analyze and discuss an assigned incident scenario and appropriate response actions, and present their findings to the class as a whole.

The course provides unique opportunities for realistic hands-on exercises with a fuel cell vehicle burn prop that simulates conditions and different accident scenarios that could be encountered during the control and suppression of a fuel cell vehicle fire. The burn prop is illustrated in Figure 1; a nearly invisible hydrogen flame is burning from the top of the fuel cell vehicle. Here the instructor is demonstrating the relative lack of radiant heat from a hydrogen flame compared to other flammable gases such as propane. 


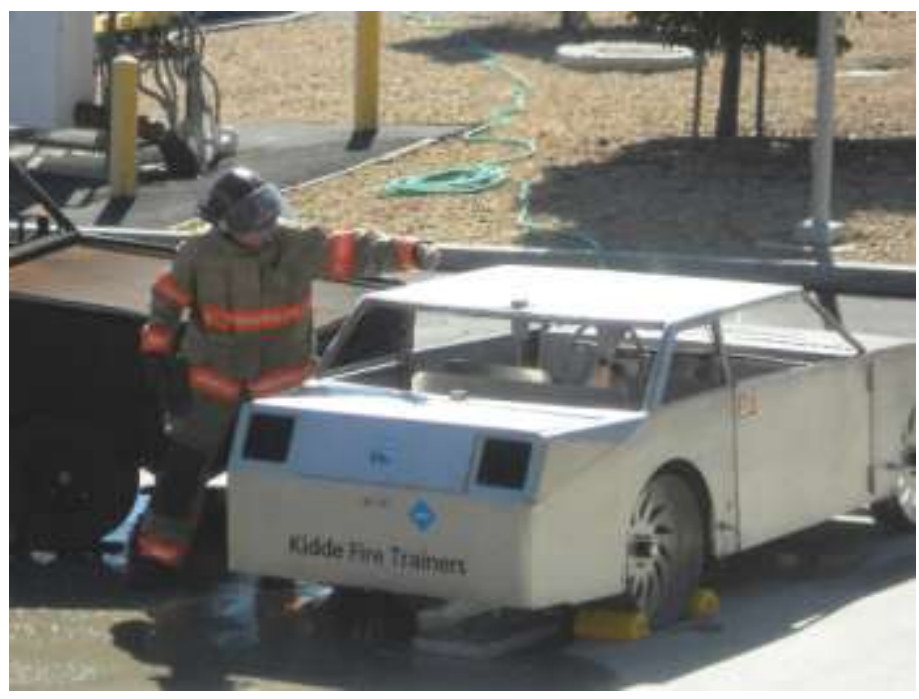

Figure 1. FCV burn prop fabricated by Kidde Fire Trainers

Figure 2 illustrates a specific accident scenario in which a "victim" is rescued from the hydrogen fuel cell vehicle while fire suppression in and around the vehicles continues.

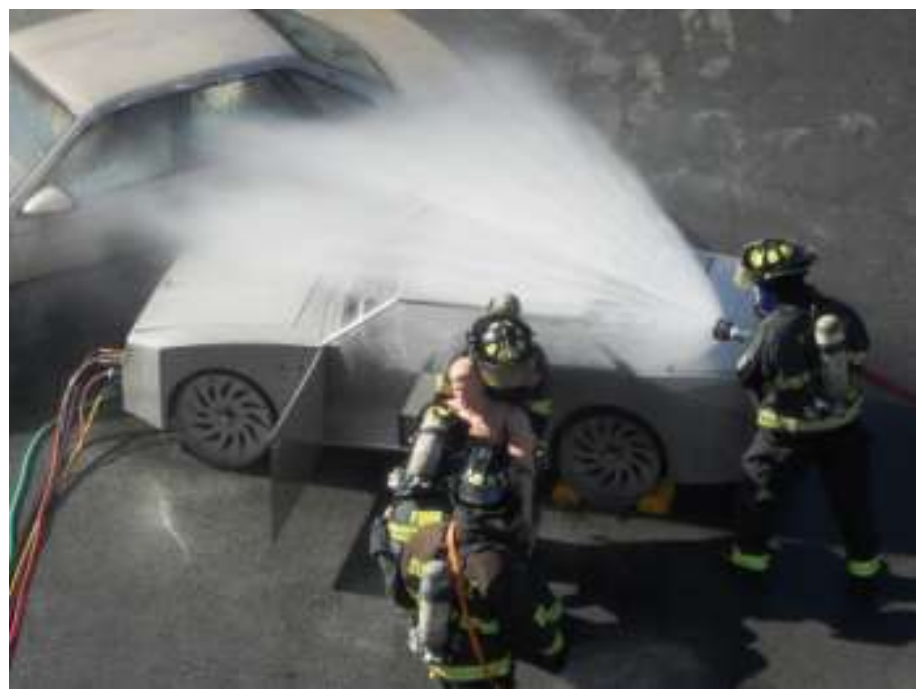

Figure 2. A team of fire fighters rescues the "victim"

More detailed discussion about the curriculum and training exercises were presented in 2011. [7] Subsequently, the operations-level course was presented to nearly 600 fire fighters in California and Hawaii in 2012/2013 as an integral part of growing initiatives toward the commercialization of hydrogen and fuel cell technologies. Feedback from participants reinforces the relevancy of this approach to first responder training:

- "I feel more comfortable with the topic of hydrogen."

- "Good course. It has taken away the mystery of a hydrogen fuel cell vehicle."

- "Very pertinent to our jobs. Answered any myths or questions about fire/hydrogen." 


\subsection{CaFCP SUPPORTING EARLY MARKET COMMUNITIES}

The California Fuel Cell Partnership (CaFCP) and its members are playing a central role in the realization of fuel cell electric vehicles and the supporting infrastructure required in California. "A California Road Map: The Commercialization of Hydrogen" [8] identifies the challenges ahead and provides the analysis to determine the appropriate number of hydrogen stations required for pre-commercial activities as well as launching early market communities.

The CaFCP began conducting first responder outreach and training in 2002 with the recognition by the automobile manufacturer members of the need to educate and familiarize firefighters even as the vehicles were in prototype. They wanted to avoid a similar reaction to hydrogen-fueled vehicles as there had been to gasoline-electric hybrids. As hybrid vehicle numbers grew and were involved in incidents, there was a paucity of education related to the high voltage systems; first responders were confonted with high voltage in vehicles they had never had to deal with previously. As the training progressed, dispelling pre-conceived ideas and getting first responders "comfortable" with hydrogen became increasingly important objectives. The first version of the emergency response guide [9], developed in collaboration with member organizations, the California State Fire Marshall and the fire departments of West Sacramento, CA and Richmond, CA, has served as the principal basis for these outreach efforts, supplemented by additional materials [10].

These early outreach efforts by the CaFCP reinforced an important point that continues to be worthy of emphasis as future first responder outreach and training needs are considered. Firefighters represent a stakeholder community with a broad definition. In addition to their responsibilities in emergency response, they are consumers and also play important roles in community acceptance and the permitting process for infrastructure. For example, the CaFCP's outreach and education efforts are helping speed the permitting and construction process for hydrogen stations in early market communities through first responder training, permitting workshops and business breakfasts. [11] Since 2004, the CaFCP has tallied over 114 such events for nearly 8,000 first responders and permitting officials.

While both the CaFCP and PNNL have separately as well as collaboratively conducted such training using vetted materials and curriculum, one can envision the day when such training will not be so specialized and will be included in the more common first responder training curricula. Stakeholders and end users, such as the NFPA and the National Fire Academy, are embracing hydrogen and fuel cell vehicle first responder training and approaches that utilize subject matter expertise accordingly.

\subsection{A NATIONAL RESOURCE TO MEET LOCAL TRAINING NEEDS}

New approaches can help meet the specific needs of first responders and presentation styles of training organizations and can complement existing training programs including the ones discussed in this paper. The experience gained from developing and deploying our other training resources led to a new product the National Hydrogen and Fuel Cell Emergency Response Training Resource - for delivering hydrogen and fuel cell-related first responder training locally to serve missions to protect life and preserve property. The resource is intended to be a single repository of current, accurate hydrogen and fuel cell-related information programs. This approach should enable government and private training organizations to develop their own programs based on consistent and current content and messaging about hydrogen and fuel cells.

This national training resource combines a slide package (Microsoft PowerPoint) with a training template (Microsoft Word) to provide a rich inventory of information and knowledge for first responder training 
organizations. The 130 slides are divided into six sections analogous to the approach taken for the operations-level classroom curriculum previously discussed:

1. Introduction and Background

2. Hydrogen and Fuel Cell Basics

3. Hydrogen-fueled Vehicles

4. Stationary Facilities

5. Managing Hydrogen-related Emergencies

6. Practical Exercises

The note pages format of the slides includes text to help instructors tailor and incorporate content to meet their needs (see Figure 3).

The training template complements the slide package with an "at-a-glance" summary to aid the user in content selection for the delivery of a variety of training regimens to various audiences. These materials are adaptable for different presentation styles, from higher level overview formats to more comprehensive classroom training. Three example uses of the slides are provided in the template for which a "slice" is illustrated in Figure 4. For purpose of comparison, these uses are named (1) L1-Overview, (2) L2-Short Course and (3) L3-Full Course.

As noted above, this training resource strongly builds on the content of the operations-level classroom curriculum developed in 2008-2009 and discussed in this paper and in the literature. [7] For example, Section 6 (Practical Exercises) provides materials that may be used for a practical exercise in a classroom training setting. Typically, instructors would assign a single incident scenario to each of several small teams of participants. Each team gets a specific amount of time to discuss their assignment and prepare a presentation to the group as a whole. Each team presents their findings and the classroom group as a whole is encouraged to comment on the presentations and share their own experiences. With this resource, instructors are free to use such materials in a manner most beneficial for the training they are delivering.

These resources are provided for download, at no-cost to the user, at the "Hydrogen Tools" portal (http://h2tools.org/fr/nt/). The portal encourages feedback from presenters and audiences on the use of these training materials. Those experiences help ensure that the development of new and updated training content and techniques are of continuing value to training organizations and emergency response personnel. Of additional note, the portal itself also provides a workspace for first responders to access other related information and discuss topics of interest within their user group (https://h2tools.org/role/first-responders). 


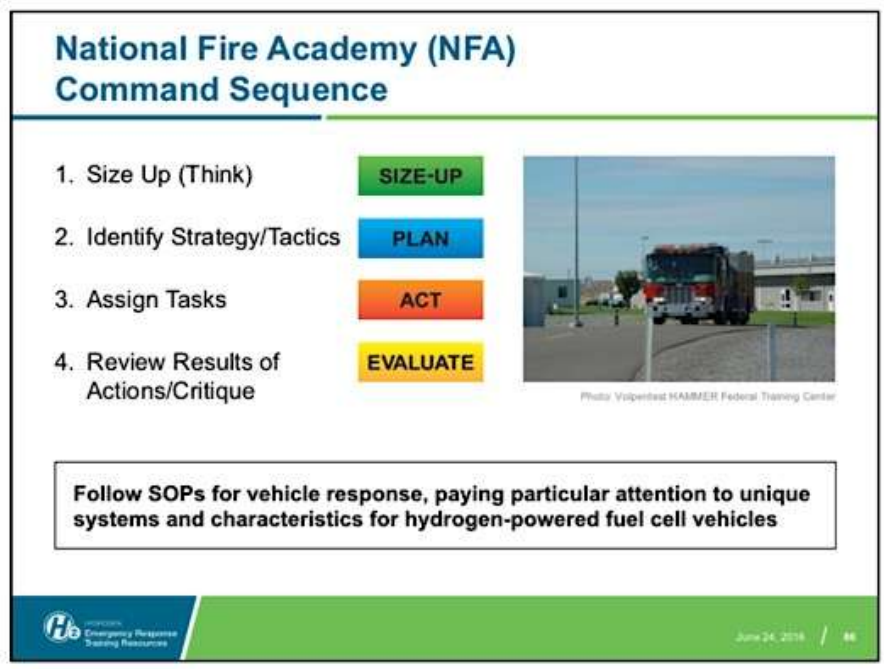

In the event of an incident in which a hydrogen vehicle or stationary facility may be involved, first responders are expected to follow their department's standard operating procedures (SOPs), guidelines (SOGs) and protocols.

I

When formulating responses to incidents involving hydrogen vehicles or stationary facilities, emergency response personnel must take into account the special properties and characteristics of hydrogen, understand the means needed to detect hydrogen leaks and flames, and follow proper response techniques.

Figure 3. An example slide/note page from the National Hydrogen and Fuel Cell Emergency Response Training Resource (Section 5 - Managing Hydrogen-related Emergencies)

\section{A TEMPLATE for TRAINING}

\section{NATIONAL HYDROGEN AND FUEL CELLS EMERGENCY RESPONSE TRAINING}

Sade \#1 What and Winy

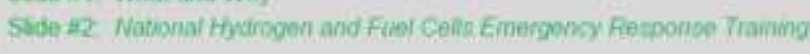

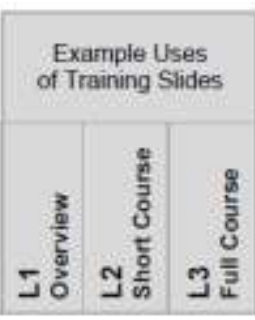

\section{Introduction and Background}

Side \#4 Fuel Cellis Overvien and Benents

Stide $\# 5 \%$ F/7 Fuel Cefis - Wisere are We Today?

Stide \#8: Diverse Finel Ceil Trangmonfation Appications

\section{Hydrogen and Fuel Cell Basics}

2.1 Hydrogen - Where does it come from and how do we use it now? Slide $\# 10$. Why Hydiogen?

Side \#11: Where Do Wo Get thdiogen?

Figure 4. National Hydrogen and Fuel Cells Emergency Response Training Template 


\subsection{PLANNING FOR THE FUTURE}

Ensuring that first responder training resources are effective requires more than general maintenance. Hydrogen course delivery methods, content and training props need to reflect the latest knowledge on hydrogen safety for the broadening application of fuel cell systems. The resources should also utilize effective training methods that meet the current goals and needs of the first responder community. The importance of these points was reinforced at a stakeholder workshop conducted in Los Angeles in April 2014 to consider what electronic safety tools would significantly benefit the next phase of hydrogen and fuel cell commercialization. [12]

With a focus on future activities, PNNL and the CaFCP convened a group of first responder trainers, facility and equipment providers and other interested persons in 2015 to consider what materials and delivery methods are best suited to enhancing the first responder learning outcomes. Recommendations were provided to serve three purposes: 1) identify enhancements for the existing training resources, 2) recommend new impactful resources and materials that should be added to the training portfolio, and 3) provide guidelines that can be used to inform the direction of future training development efforts. Results suggested that improved images and videos, new props and consideration of virtual reality tools could help improve the instructional quality and potential reach of first responder hydrogen safety training resources in a cost effective manner. [13]

\subsection{CONCLUDING THOUGHTS}

Collaborative efforts are key to first responder training products and experiences. As hydrogen and fuel cell-related technologies and systems are being developed, deployed and commercialized, the role played by first responders becomes increasingly important to the success of these worldwide efforts.

Collaborative efforts have been an important aspect of the work that has been discussed in this paper and opportunities for valuable collaboration on a global basis are starting to take hold.

The HyResponse project (http://hyresponse.eu/), supported by the European Commission's Fuel Cell and Hydrogen Joint Undertaking (FCH-JU), aims "to facilitate safer deployment of FCH systems and infrastructure". The core program covers (1) educational hydrogen safety training, (2) operational training on mock-up real scale facility installations, and (3) innovative virtual reality training reproducing entire accident scenarios. A September 2014 project workshop provided an opportunity for the U.S. Department of Energy's first responder training work to be presented and discussed in the context of developing new collaborative initiatives. $[14,15]$ A future collaboration may include a joint training session in the U.S. which includes resources from PNNL/CaFCP and the HyResponse project.

The authors believe that mutual benefits can be achieved by such collaborations that build upon the goals, objectives and successes achieved by national programs on first responder training.

\subsection{ACKNOWLEDGMENTS}

The authors wish to thank the U.S. Department of Energy's Fuel Cell Technologies Office (Sunita Satyapal, Director) for their support of this work. The contributions to this work by colleagues and organizations collaborating with PNNL and CaFCP are gratefully acknowledged. 


\subsection{REFERENCES}

1. Barilo, N., "The H Factor," NFPA Journal, May/June 2014. (available online at (http://www.nfpa.org/newsandpublications/nfpa-journal/2014/may-june-2014/features/all-thingshydrogen)

2. U.S. Code of Federal Regulations (CFR) 1910.120, Revised 1999, Occupational Safety and Health Standards, Hazardous waste operations and emergency response, downloadable from: http://www.access.gpo.gov/nara/cfr/waisidx_99/29cfrv5_99.html.

3. NFPA 472: Standard for Competence of Responders to Hazardous Materials/Weapons of Mass Destruction Incidents, 2008 Edition, can be purchased from: http://www.nfpa.org/aboutthecodes/AboutTheCodes.asp?DocNum=472\&cookie_test=1.

4. Fassbender, L.L., Kinzey, B.R., and Akers, B.M., "Safety Training for the Hydrogen Economy," Society of Automotive Engineers (SAE) 2006 World Congress \& Exhibition, Detroit, paper 2006-010329, 2006.

5. Fassbender, L.L., Akers, B.M., and Cooper, C., "Introduction to Hydrogen Safety for First Responders," Firehouse 32, No. 8, August 2007, p. 158.

6. Fassbender, L.L, Hydrogen Emergency Response: Training for First Responders (Training Manual), Pacific Northwest National Laboratory, PNNL-18495, 2009.

7. Elmore, M.R., Fassbender, L.L., Hamilton, J.J. and Weiner, S.C., "Hydrogen Emergency Response Training for First Responders," PNNL-SA-79009/82560, International Conference on Hydrogen Safety, San Francisco, CA, September 12-14, 2011.

8. California Fuel Cell Partnership, A California Road Map: The Commercialization of Hydrogen; The realization of fuel cell electric vehicles and supporting infrastructure requires a road map for investments in fuel cell electric vehicles and hydrogen fueling stations, June 2012. http://cafcp.org/sites/files/A\%20California\%20Road\%20Map\%20June\%202012\%20\%28CaFCP\%20t echnical\%20version\%29 1.pdf

9. California Fuel Cell Partnership, "Emergency Response Guide, Fuel Cell Vehicles and Hydrogen Fueling Stations," Version 2.0, August 2004.

10. California Office of the State Fire Marshal, FSTEP Course, Emergency Response to Alternative Fuel Vehicles (2009) (http://osfm.fire.ca.gov/training/pdf/alternativefuelvehicles/Altfuelintroduction.pdf)

11. California Fuel Cell Partnership, Progress and 2011 Actions for Bringing Fuel Cell Vehicles to the Early Commercial Market in California, February 2011, http://cafcp.org/sites/files/CaFCPProgressand2011Actions_0.pdf.

12. Barilo, N., "Electronic Safety Resource Tools - Supporting Hydrogen and Fuel Cell Commercialization," PNNL-23704, September 2014.

13. Goins, J., Barilo, N. And Hamilton, J.J., "Needs Analysis and Recommendations on First Responder Training on Hydrogen Safety (Draft)," March 2015.

14. Carey, K., "U.S. Perspectives on Hydrogen and Fuel Cells," International Workshop on Hydrogen Safety for First Responders, French Academy for Fire, Rescue and Civil Protection Officers (ENSOSP), Aix-en-Provence, France, September 3-4, 2014. (see http://hyresponse.eu/workshop.php)

15. Weiner, S.C., "First Responder Training - Resources and Future Direction, "PNNL-SA-104297, International Workshop on Hydrogen Safety for First Responders, French Academy for Fire, Rescue and Civil Protection Officers (ENSOSP), Aix-en-Provence, France, September 3-4, 2014. (see http://hyresponse.eu/workshop.php) 